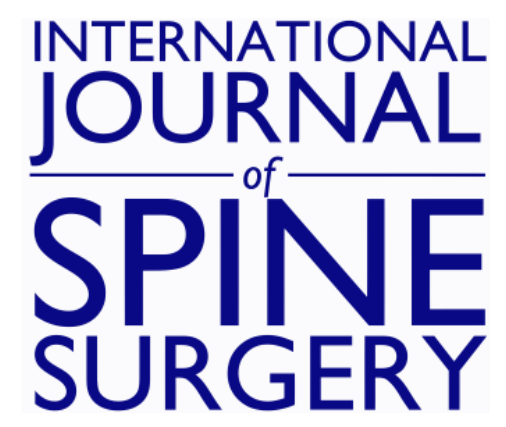

\title{
Cortical and Standard Trajectory Pedicle Screw Fixation Techniques in Stabilizing Multisegment Lumbar Spine with Low Grade Spondylolisthesis
}

Wayne K. Cheng and Serkan Inceoglu

Int J Spine Surg 2015, 9 ()

doi: https://doi.org/10.14444/2046

http://ijssurgery.com/content/9/46

This information is current as of April 26, 2023.

Email Alerts Receive free email-alerts when new articles cite this article. Sign up at:

http://ijssurgery.com/alerts

The International Journal of Sphine Surgerbittp://ijssurgery.com/ by guest on April 26, 2 2397 Waterbury Circle, Suite 1,

Aurora, IL 60504, Phone: +1-630-375-1432

(C) 2015 ISASS. All Rights Reserved. 


\section{Cortical and Standard Trajectory Pedicle Screw Fixation Techniques in Stabilizing Multisegment Lumbar Spine with Low Grade Spondylolisthesis}

Wayne K. Cheng, MD, Serkan İnceoğlu, PhD

Department of Orthopaedic Surgery, Loma Linda University School of Medicine, Loma Linda, CA, USA

\section{Abstract}

\section{Background}

Cortical screw (CS) fixation has been recently proposed as an alternative to the standard pedicle screw (PS) fixation technique. Biomechanical studies involving individual screw pullout and single level motion segment stabilization showed comparable performance of both techniques. However, whether this new fixation technique can be applied to the stabilization of multilevel lumbar segments with significant destabilization has been unclear.

Purpose

To compare stability of CS fixation to the traditional PS fixation in an unstable 3 level spondylolisthesis model.

\section{Study Design}

This is a biomechanical study comparing cortical trajectory pedicle screw fixation to traditional trajectory pedicle screw fixation in an unstable cadaveric model using nondestructive flexibility test.

\section{Methods}

Eight fresh frozen cadaveric lumbar spines (T12-S1) were obtained. After intact baseline testing, a 3-level lowgrade spondylolisthesis was simulated at the L1-4. Each specimen was instrumented with the PS and CS fixation systems. Standard nondestructive flexibility test was performed. Range of motion at each level was compared between the constructs during flexion-extension, lateral bending, and axial rotation.

\section{Results}

The destabilization model significantly increased the ROM in all planes $(\mathrm{P}<0.05)$. Both fixation techniques provided significant reduction in the ROM $(\mathrm{P}<0.05)$. There was no significant difference in ROM between the PS and CS groups in any of planes $(\mathrm{P}>0.05)$.

\section{Conclusions}

Cortical trajectory pedicle screw fixation provided stabilization to multilevel lumbar segment with low-grade spondylolisthesis comparable to the standard trajectory pedicle screw construct.

KEYWords: CoRtical bone tRajeCtory, PEDICLE SCREW, CORTICAL SCREW, LUMBAR SPINE, LOW GRADE SPONDYLOLISTHESIS MODEL, BIOMECHANICS VOLUME 9 ARTICLE 46 DOI: 10.14444/2046

\section{Introduction}

Pedicle screw fixation has been accepted as the mainstay of instrumentation in arthrodesis of the lumbar spine. Since the introduction of pedicle screw by Boucher in $1959,{ }^{1}$ multiple trajectories and insertion techniques have been described for screw placement. ${ }^{2,3}$ The commonly practiced convergent trajectory today was popularized by Friedrich Magerl in the 1980 's. ${ }^{3}$
There are two main pitfalls with this technique.

First, in order to place screw in this axis, significant muscle dissection and lateral exposure are required. Although the triangulated screw constructs formed by placing screws along the anatomic axis of the pedicle have increased construct stability and pullout strength, ${ }^{4,5}$ this trajectory could be potentially difficult in patients with large body habitus. ${ }^{6}$ The second weakness of the traditional pedicle screw fixation is the elevated risk of failure in osteoporotic bone. The 
fixation quality of the pedicle screw relies heavily on the quality of the trabecular bone in the vertebra. Biomechanical studies have shown that pullout and toggle performance of pedicle screws significantly deteriorated when bone quality decreased. ${ }^{?}$

Multiple authors have proposed alternative trajectory. In 2007, Sterba et al. suggested, in a pedicle screw fatigue study, that a straight trajectory was more stable than the traditional convergent trajectory. ${ }^{6}$ This was later supported by İnceoğlu et al. using screws placed by a similar trajectory in a fatigue study. ${ }^{8} \mathrm{In}$ 2009 , Santoni et al. proposed a new cortical bone trajectory. In this new technique, pedicle screws engage the cortical bone around the pedicle isthmus, unlike the traditional technique which relies on the trabecular bone in the pedicle and vertebra. The cortical trajectory takes advantage of the cortical mass of the pedicle and vertebral body, obtaining multiple points of fixation among the dorsal cortex at the site of insertion, the medial pedicle wall, the lateral pedicle wall, and the curvature of the vertebral body cortex. ${ }^{9}$ This cortical screw (CS) trajectory has been shown to be a successful alternative to the standard pedicle screw (PS) fixation in biomechanical studies of single level construct. ${ }^{10,11}$

Although the CS fixation has been shown to provide stability to the spine comparable to the PS fixation in a single motion segment, it is still not clear whether this finding would hold true in the case of a long segment fixation. More importantly, the question of how the $\mathrm{CS}$ would perform in the presence of significant instability still remains unanswered. Therefore, the purpose of the current study was to analyze the stability of a multi-level lumbar spine with low-grade spondylolisthesis at each level, instrumented with either the CS or PS fixations systems. Our hypothesis was that the initial stability provided by the CS would be comparable to that of the PS in a lumbar spine with a 3 level low-grade spondylolisthesis.

\section{Materials and Methods}

\section{Study Design}

All specimens were tested in intact condition for establishing baseline range of motion (ROM) values using a flexibility protocol. Then, a low-grade spondy- lolisthesis was simulated at three levels (L1-2, L2-3, and L3-4). After testing for destabilized condition, each spine was instrumented with the CS and PS systems sequentially and ROM measurement was repeated.

\section{Specimen Preparation}

For this project, 8 fresh frozen cadaveric lumbar spines (S1-T12) were obtained $(\mathrm{N}=8)$. All spines were scanned for bone mineral density (BMD) using a dual-energy X-ray absorptiometry (DEXA) scanner (Table 1). For testing, all spines were embedded in gypsum cement (Casting Plaster, US Gypsum, Chicago, IL) at the $\mathrm{T} 12$ and $\mathrm{S} 1$ vertebrae.

\section{Instability Model}

After intact baseline measurements, a low-grade spondylolisthesis was simulated at three levels (L1-2, L2-3, and L3-4) by bilateral facetectomy, resection of the ligamentum flavum and posterior and anterior longitudinal ligaments (including the outermost layer of the annulus), and nucleotomy. ${ }^{12}$ The testing was repeated to calculate the damage caused by the destabilization procedures.

\section{Instrumentation}

Each specimen was instrumented with the standard and cortical trajectory pedicle screw fixation systems with an alternating order to prevent bias. The starting point for the CS was at the level of inferior portion of transverse process, mid superior facet, approximately $2 \mathrm{~mm}$ medial to the lateral margin of pars interarticularis (Figure 1). The trajectory was approximately $25^{\circ}$ cephalad and $8^{\circ}$ laterally as de-

Table 1. Age, gender, and T-score data for cadavers used in the study.
\begin{tabular}{|l|r|r|r|}
\hline Spine ID & Age & Gender & T-Score \\
\hline 1 & 69 & M & -3.50 \\
\hline 2 & 69 & F & -3 \\
\hline 3 & 50 & M & -1.3 \\
\hline 4 & 80 & F & -0.6 \\
\hline 5 & 78 & M & 2.8 \\
\hline 6 & 78 & M & -0.5 \\
\hline 7 & 72 & F & -1.3 \\
\hline 8 & 79 & M & 0.2 \\
\hline
\end{tabular}


scribed by Matsukawa et al. ${ }^{9}$ We used a high-speed surgical burr (Midas Rex Legend, Medtronic, Minneapolis, MN) with a match head drill bit of $1.7 \mathrm{~mm}$ to start the screw hole and form the trajectory. After tapping $(5.5 \mathrm{~mm}), 5.5 \times 30 \mathrm{~mm}$ polyaxial cortical screws (Nuvasive, San Diego, CA) were inserted (Figure 2).

The starting point for the PS was at the junction between the mid-transverse process and lateral aspect of superior facet. Starting point was made by the high-speed surgical drill as described above, followed by a standard Lenke pedicle probe. Tap was not used. Polyaxial pedicle screws with size of $5.5 \times 45$ $\mathrm{mm}$ were inserted (NuVasive, San Diego, CA) by aiming medially into the center of the vertebral body. This particular trajectory was chosen because it provided the least interaction of the PS and CS holes among other possible insertion points and angles for the PS technique. We kept the screw diameters similar in both groups for fair comparison. The pedicle screw diameter of $5.5 \mathrm{~mm}$ might be slightly smaller than the generally preferred size $(6.5 \mathrm{~mm})$ for lumbar spine surgery; however, the use of $5.5 \mathrm{~mm}$ screw is not uncommon in pedicle screw related research. ${ }^{13-15}$ In addition, Kueny et al. demonstrated that the tangential loading of $5.5 \mathrm{~mm}$ and $6.5 \mathrm{~mm}$ pedicle screws only showed a statistically insignificant $5 \%$ difference in the failure load. ${ }^{16}$

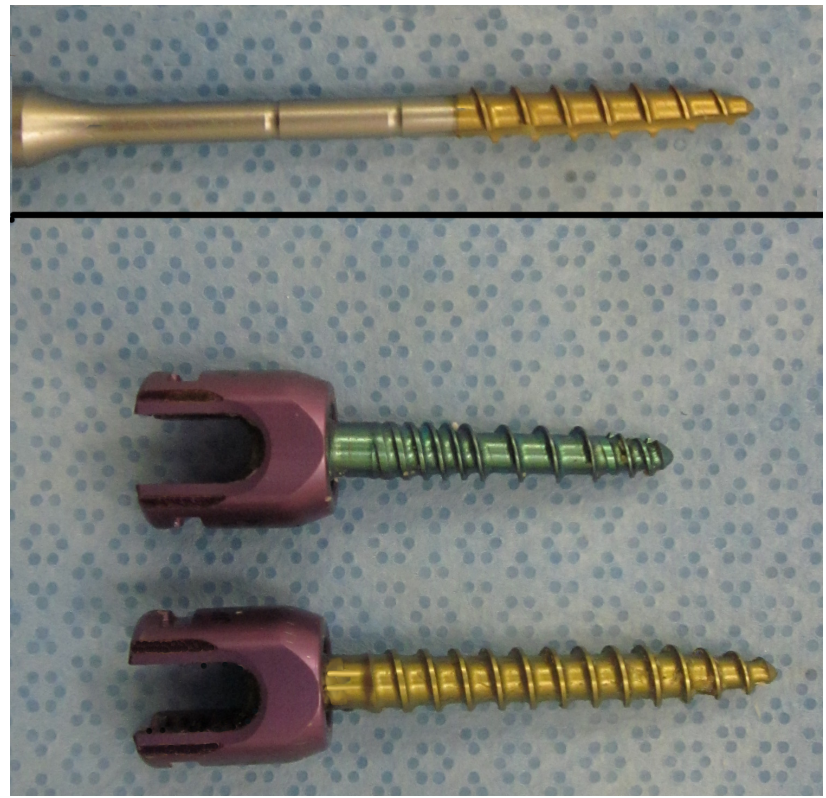

Fig. 1. The screws and tap. The pedicle screws $(5.5 \times 45 \mathrm{~mm})$ and cortical screws $(5.5 \times 30 \mathrm{~mm})$ were inserted after tapping $(5.5 \mathrm{~mm})$.
After 8 screws were placed at the L1-4, two $5.5 \mathrm{~mm}$ titanium alloy rods were contoured and secured to the screws using locking nuts and a torque wrench (NuVasive, San Diego, CA). During contouring and tightening, care was taken to maintain natural posture of the lumbar spine. The presence of the intact adjacent levels allowed physiological and homogeneous loading at the instrumented levels.

\section{Biomechanical Testing}

Each specimen was secured into a 6 degree of freedom spine testing fixture (Figure 3 ). We only locked the vertical translation motion because the coupled forces were too small (about 0-20N) compared to the linear axis of the load cell and resulted in suboptimal linear load control of the crosshead. We observed

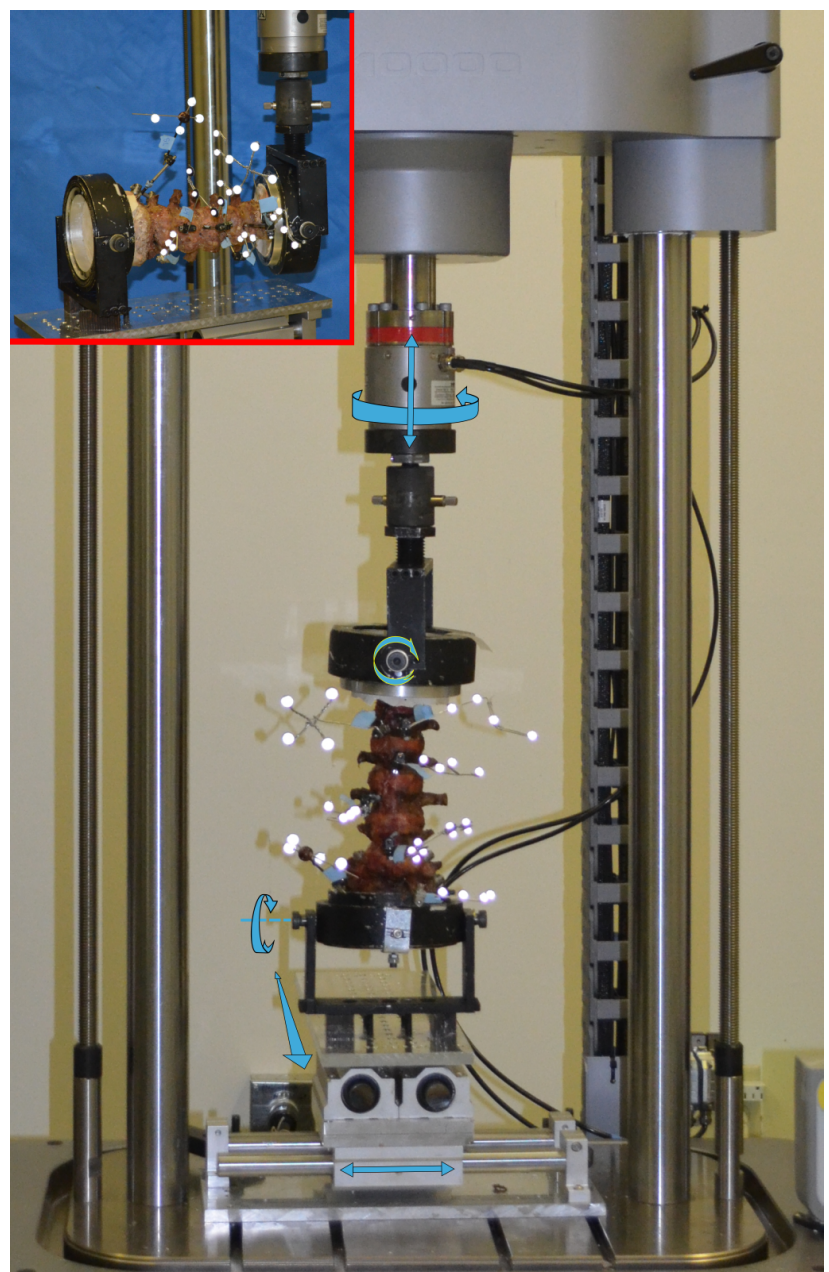

Fig. 2. The custom-designed apparatus allowed a non-constraint motion for the spine in all three planes of motion during pure moment application. The reflective markers were used to detect interlevel motion. The inset illustrates the position of the specimen and fixture during sagittal and lateral bending. During switching from lateral bending to sagittal bending, the specimen was rotated $90^{\circ}$ around its caudo-cephelad axis. 
that the absence of that degree-of-freedom did not significantly affect the motion and thus we did not hesitate to lock it for the accuracy of the other motions. The specimens were tested in all planes of motion using the flexibility protocol. A pure moment of $7.5 \mathrm{Nm}$ was applied to the specimens at $1 \mathrm{deg} / \mathrm{s}$ for 6 cycles. The motion of the spine was monitored via reflective markers and analyzed with a motion analysis system (Vicon, Oxford, UK). The interlevel motion was calculated using a custom MATLAB code utilizing the resources available at the International Society of Biomechanics online archives. The local coordinate system was established by digitizing the L1-4 vertebrae of each specimen before each test.

\section{Data Analysis}

The applied moment and motion data from the last cycle were used for statistical analysis. The paired design of the experiment allowed minimizing the inter-specimen variability. A two-way ANOVA for repeated measures test (factors: effect of instrumentation and spinal level) was used to detect any differences among the PS and CS groups within 95\% confidence. Because this experiment had a paired design, we also looked into whether the effect of construct testing order, i.e., testing PS first or CS first, affected our findings. In addition, linear regression analyses were run, considering each instrumented level individually, to determine the correlation of the PS and CS data with the degree of instability. An ANCOVA test was run to determine whether the slopes of the

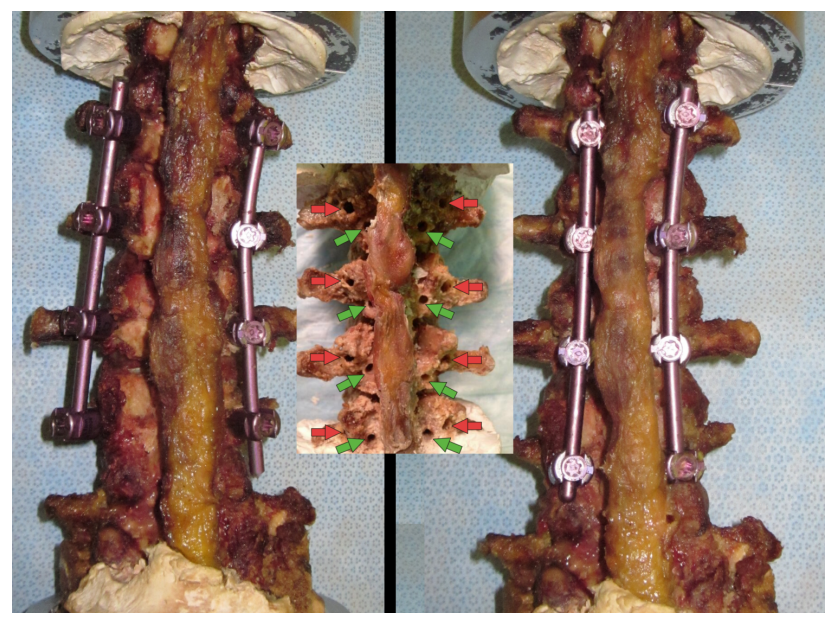

Fig. 3. Each specimen was instrumented (L1-4) and tested with both standard and cortical trajectory pedicle screws. Due to the difference in screw start points and insertion trajectories, there was minimal interaction between the constructs. two regression lines were different from each other. We also analyzed the regression of the ROM with Tscore and vertebral BMD for both groups. For the regression with T-score, individual ROM values were summed to obtain a measure of fixation for each spine. For the regression with the vertebral BMD, all instrumented levels were pooled and the BMDs of the two vertebrae in each motion segment were averaged.

\section{Results}

All ROM data were normalized with intact values prior to statistical analyses (Table 2). The statistical analysis showed that the destabilization model used in the study significantly increased the ROM in all planes $(\mathrm{P}<0.05)$. Two spines were completely ruptured during testing for destabilized condition. Both fixation techniques provided significant reduction in the ROM of the destabilized spines in all planes (Figure 4, Figure 5, Figure 6, $\mathrm{P}<0.05$ ). In the instrumented condition, the ROM was significantly less than the intact ROM in sagittal and lateral bending $(\mathrm{P}<0.05)$, but not in axial rotation $(\mathrm{P}>0.05)$. There was no significant difference in the ROM between the PS and $\mathrm{CS}$ groups in any of planes $(\mathrm{P}>0.05)$. A mixed-design analysis of variance showed that the order of testing of constructs did not have any significant effect on the ROM of the constructs $(\mathrm{P}>0.05)$.

The ROMs of both groups were significantly correlated with the level of instability in sagittal and axial planes $(\mathrm{P} \leq 0.05)$ but not in lateral plane $(\mathrm{P}>0.05)$ (Table 3). The slopes of the regression lines were not different from each other in any of the planes of motion $(\mathrm{P}>0.05)$.

In sagittal bending and axial rotation, the fixation power of both groups seemed to be degraded with increasing instability. Every one unit rotation increase in the instability caused a decrease in the fixation quality by $0.17-0.28$ unit rotation in the CS system and 0.25-0.29 unit rotation in the PS system (note that here 1 unit rotation is $100 \%$ intact-ROM degree due to the normalization). These amounts of change in the fixation were not significantly different between the fixation techniques $(\mathrm{P}>0.05)$. 
Our specimens appeared to have more instability in

Table 2. Range of motion values (in degrees) (mean \pm standard deviation).

\begin{tabular}{|c|c|c|c|c|}
\hline & & L4-3 & L3-2 & L2-1 \\
\hline \multicolumn{5}{|l|}{ Sagittal } \\
\hline & intact & $8.76 \pm 3.58$ & $8.37 \pm 2.77$ & $7.43 \pm 2.29$ \\
\hline & destab & $13.01 \pm 1.45$ & $10.52 \pm 2.59$ & $12.67 \pm 2.84$ \\
\hline & PS & $3.18 \pm 1.78$ & $0.28 \pm 1.09$ & $1.53 \pm 1.63$ \\
\hline & CS & $2.58 \pm 1.60$ & $1.73 \pm 0.65$ & $3.55 \pm 2.97$ \\
\hline \multicolumn{5}{|l|}{ Lateral } \\
\hline & intact & $9.37 \pm 2.51$ & $9.82 \pm 3.44$ & $7.36 \pm 1.50$ \\
\hline & destab & $14.77 \pm 4.92$ & $11.09 \pm 2.46$ & $11.84 \pm 2.62$ \\
\hline & PS & $1.40 \pm 0.56$ & $0.32 \pm 0.53$ & $0.68 \pm 0.98$ \\
\hline & CS & $1.93 \pm 0.77$ & $0.96 \pm 0.25$ & $3.51 \pm 1.91$ \\
\hline \multicolumn{5}{|l|}{ Axial } \\
\hline & intact & $4.28 \pm 2.61$ & $4.91 \pm 3.25$ & $2.50 \pm 1.06$ \\
\hline & destab & $12.50 \pm 4.75$ & $11.46 \pm 3.75$ & $9.73 \pm 4.12$ \\
\hline & PS & $2.15 \pm 0.99$ & $0.83 \pm 1.13$ & $1.29 \pm 1.28$ \\
\hline & CS & $2.10 \pm 1.01$ & $2.76 \pm 1.46$ & $3.45 \pm 1.61$ \\
\hline
\end{tabular}

\section{Sagittal Bending}

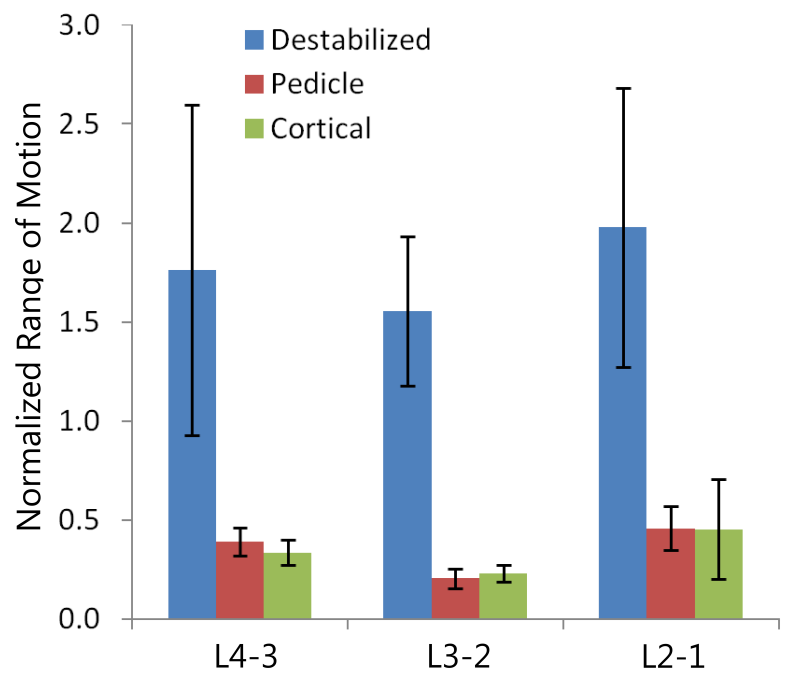

Fig. 4. The interlevel ROM for destabilized and instrumented spines (L1-4) as normalized with intact in sagittal bending. Instability was significantly reduced by both fixation systems. There was no difference in ROM between both constructs (mean \pm standard deviation). axial plane than sagittal plane. The variability in the instability could explain only $16-24 \%$ of the changes in the ROM in instrumented spine in sagittal motion and $32-41 \%$ in the axial motion. The loss of fixation quality in the axial motion can be explained by the lack of crosslinks in our constructs.

\section{Neither the PS nor the CS group was significantly}

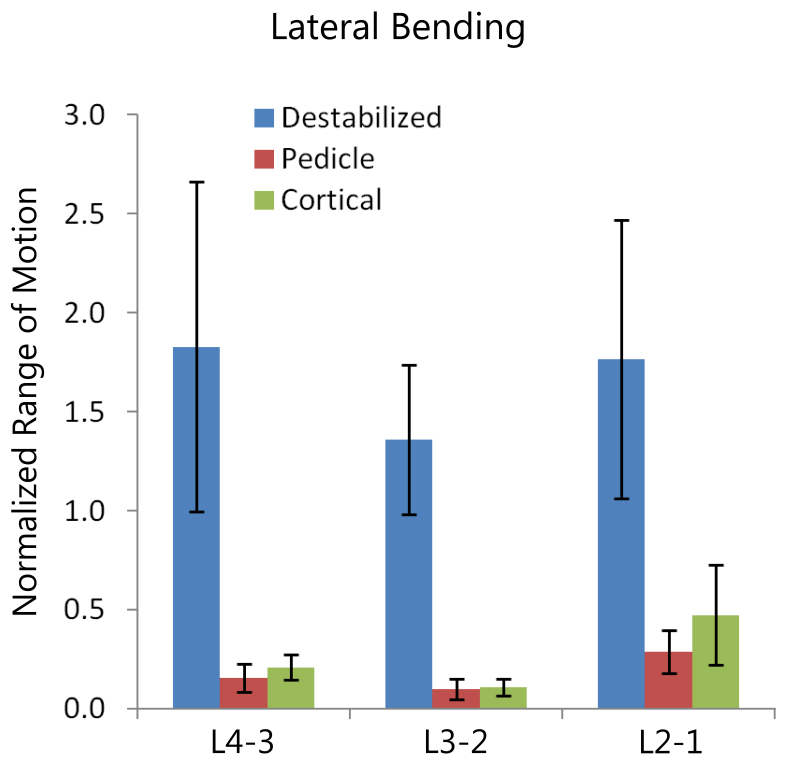

Fig. 5. The interlevel ROM for destabilized and instrumented spines (L1-4) as normalized with intact in lateral bending. Instability was significantly reduced by both fixation systems. There was no difference in ROM between both constructs (mean \pm standard deviation).

\section{Axial Rotation}

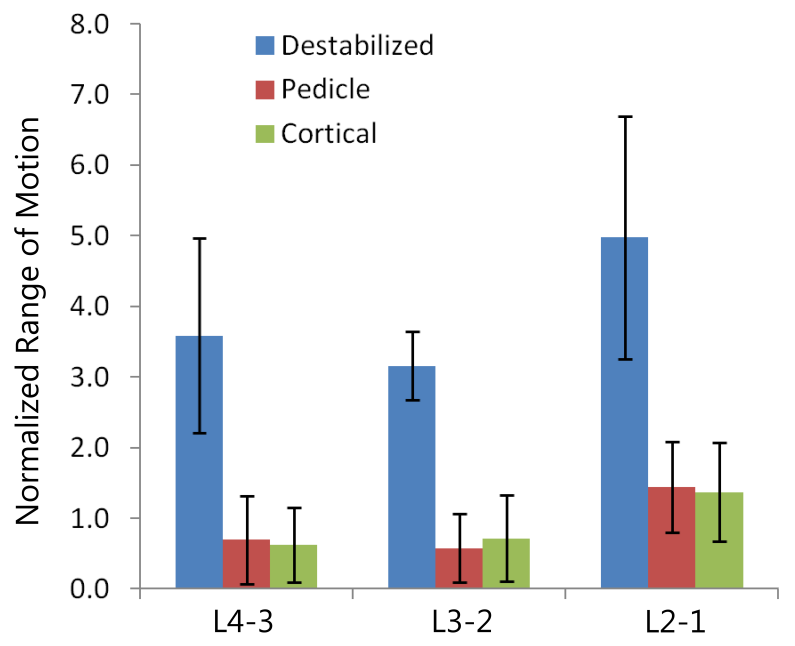

Fig. 6. The interlevel ROM for destabilized and instrumented spines (L1-4) as normalized with intact in axial rotation. Instability was significantly reduced by both fixation systems. There was no difference in ROM between both constructs (mean \pm standard deviation). 
correlated with the $\mathrm{T}$-score $(\mathrm{P}>0.05)$.

\section{Discussion}

Cortical screws have been increasingly used for the last few years mainly as a minimally invasive method to achieve stabilization in one or two level degenerative spinal surgeries. Most surgeons would favor the PS over CS in treating unstable spinal pathology. We specifically chose an unstable model with spondylolisthesis at three lumbar levels to make the comparison between two systems more clinically relevant and biomechanically challenging. The finding of this study was surprisingly similar to a prior study done by Perez-Orribo et al., ${ }^{17}$ in which the investigators were able to demonstrate that with intact disc or with interbody fusion, the PS and CS fixations provided similar stability to a single motion segment.

It is worthwhile to mention that during the testing after destabilization, two specimens sustained a complete dissociation due to rupture of all three columns. Those specimens were grossly loose, therefore beyond our ability to measure the range of motion. Using the two specimens as the most extreme unstable model, we were not able to demonstrate the difference in range of motion testing after the specimens were stabilized with either CS or PS systems.

The original study on the comparison of the CS to PS evaluated the pullout and plow-out behavior of both screws, where the screws were pulled out axially or by application of extension bending moment combined with pullout. ${ }^{10}$ It was shown that the CS had a similar pullout and plow-out properties as the PS, with a tendency to be better in pullout. During our

Table 3. Results of regression analysis.
\begin{tabular}{|l|r|r|r|r|r|r|}
\hline & Sagittal & \multicolumn{2}{|r|}{ Lateral } & \multicolumn{2}{|c|}{ Axial } \\
\hline Slope & 0.25 & 0.17 & 0.03 & 0.08 & 0.29 & 0.28 \\
\hline Intercept & -0.07 & 0.04 & 0.13 & 0.12 & -0.16 & -0.09 \\
\hline P-value & 0.02 & 0.05 & 0.24 & 0.14 & 0.01 & 0.00 \\
\hline R & 0.24 & 0.16 & 0.03 & 0.07 & 0.32 & 0.41 \\
\hline $\begin{array}{l}\text { Are the slopes different (P- } \\
\text { value) ? }\end{array}$ & & 0.56 & & 0.49 & & 0.99 \\
\hline
\end{tabular}

study, we were able to cut one vertebra with clear view of sagittal trajectory of the CS. It appeared that with the caudally positioned start point and the caudal-to-cephelad trajectory, the CS purchases bone closer to the inferior and superior thick cortical bone of the pedicle isthmus (Figure 7). This could theoretically explain why cortical screws have high unidirectional toggling resistance.

It was counterintuitive to find that our regression analysis failed to demonstrate any influence of bone density on the range of motion of either construct. Similarly, Santoni et al. were unable to show any effect of bone density on the screw pullout or plowout. There may be multiple explanations. First, we think that the non-destructive short-term cyclic loading might not show the influence of bone density to the spinal flexibility because of the other stabilizing elements of the construct. Secondly, the degradation of bone structure due to aging might not be to the level to show a pronounced impact on the screw instability in our specimens. Thirdly, the bone density measurements might be skewed due to the advanced degree of osteoarthritis in some of our samples. This would falsely elevate the bone density ${ }^{18}$ and thus hinder the regression analysis.

Our findings are limited to a short-term analysis of the constructs. Although we showed that both constructs had similar stability, we cannot speculate on how they would maintain this stability under longterm cyclic loading.

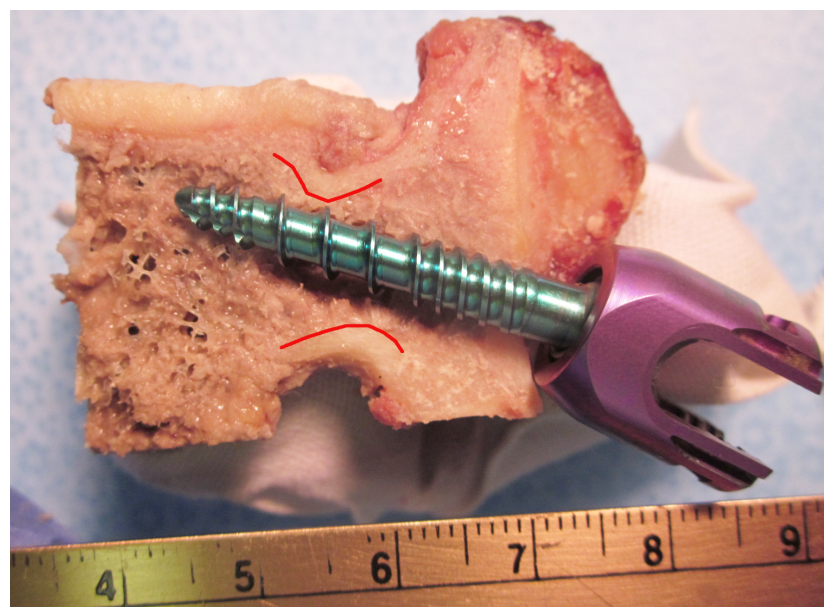

Fig. 7. The sagittal cross-sectional view of cortical trajectory. The superior and inferior cortices of the pedicle isthmus provide dense bone and might contribute increased screw stability. 


\section{Conclusions}

The CS construct provided stabilization to multilevel lumbar segment with multilevel low-grade spondylolisthesis comparable to the PS construct. The bone density did not seem to influence the quality of the stabilization. Fixation quality provided by both systems was influenced by the level of segmental instability to a similar degree.

\section{Acknowledgements}

The authors thank NuVasive, Inc. for donating instrumentations and $\mathrm{K} 2 \mathrm{M}$, Inc. for donating cadavers for this study.

\section{References}

1. Boucher HH. A method of spinal fusion. J Bone Joint Surg Br. 1959;41-b(2):248-59.

2. Roy-Camille R, Saillant G, Berteaux D, Salgado

$\mathrm{V}$. Osteosynthesis of thoraco-lumbar spine fractures with metal plates screwed through the vertebral pedicles. Reconstruction surgery and traumatology. 1976;15:2-16.

3. Magerl FP. Stabilization of the lower thoracic and lumbar spine with external skeletal fixation. Clin Orthop Relat Res. 1984;(189):125-41.

4. Barber JW, Boden SD, Ganey T, Hutton WC. Biomechanical study of lumbar pedicle screws: does convergence affect axial pullout strength? J Spinal Disord. 1998;11(3):215-20.

5. Cook SD, Salkeld SL, Whitecloud TS, 3rd, Barbera J. Biomechanical evaluation and preliminary clinical experience with an expansive pedicle screw design. J Spinal Disord. 2000;13(3):230-6.

6. Sterba W, Kim DG, Fyhrie DP, Yeni YN, Vaidya $\mathrm{R}$. Biomechanical analysis of differing pedicle screw insertion angles. Clin Biomech (Bristol, Avon). 2007;22(4):385-91.

7. Cook SD, Salkeld SL, Stanley T, Faciane A, Miller SD. Biomechanical study of pedicle screw fixation in severely osteoporotic bone. Spine J.

2004;4(4):402-8.

8. Inceoglu S, Montgomery WH, Jr., St Clair S, McLain RF. Pedicle screw insertion angle and pullout strength: comparison of 2 proposed strategies. J
Neurosurg Spine. 2011;14(5):670-6.

9. Matsukawa $\mathrm{K}$, Yato $\mathrm{Y}$, Nemoto $\mathrm{O}$, Imabayashi $\mathrm{H}$, Asazuma T, Nemoto K. Morphometric measurement of cortical bone trajectory for lumbar pedicle screw insertion using computed tomography. J Spinal Disord Tech. 2013;26(6):E248-53.

10. Santoni BG, Hynes RA, McGilvray KC, et al. Cortical bone trajectory for lumbar pedicle screws. Spine J. 2009;9(5):366-73.

11. Crawford NR, Yuksel KZ, Dogan S, et al. Trajectory analysis and pullout strength of self-centering lumbar pedicle screws. J Neurosurg Spine.

2009;10(5):486-91.

12. Crawford NR, Cagli S, Sonntag VK, Dickman

$\mathrm{CA}$. Biomechanics of grade I degenerative lumbar spondylolisthesis. Part 1: in vitro model. J Neurosurg. 2001;94(1 Suppl):45-50.

13. Cunningham BW, Lewis SJ, Long J, Dmitriev AE, Linville DA, Bridwell KH. Biomechanical evaluation of lumbosacral reconstruction techniques for spondylolisthesis: an in vitro porcine model. Spine (Phila Pa 1976). 2002;27(21):2321-7.

14. Harris BM, Hilibrand AS, Savas PE, et al.

Transforaminal lumbar interbody fusion: the effect of various instrumentation techniques on the flexibility of the lumbar spine. Spine (Phila Pa 1976).

2004;29(4):E65-70.

15. Beaubien BP, Derincek A, Lew WD, Wood KB. In vitro, biomechanical comparison of an anterior lumbar interbody fusion with an anteriorly placed, low-profile lumbar plate and posteriorly placed pedicle screws or translaminar screws. Spine (Phila $\mathrm{Pa}$ 1976). 2005;30(16):1846-51.

16. Kueny RA, Kolb JP, Lehmann W, Puschel K, Morlock MM, Huber G. Influence of the screw augmentation technique and a diameter increase on pedicle screw fixation in the osteoporotic spine: pullout versus fatigue testing. Eur Spine J.

2014;23(10):2196-202.

17. Perez-Orribo L, Kalb S, Reyes PM, Chang SW, Crawford NR. Biomechanics of lumbar cortical screw-rod fixation versus pedicle screw-rod fixation with and without interbody support. Spine (Phila Pa 1976). 2013;38(8):635-41.

18. Liu G, Peacock M, Eilam O, Dorulla G, Braunstein E, Johnston CC. Effect of osteoarthritis in the lumbar spine and hip on bone mineral density and di- 
agnosis of osteoporosis in elderly men and women.

Osteoporosis International. 1997;7(6):564-9.

\section{Disclosures}

The authors declare no relevant disclosures.

\section{Corresponding Author}

Wayne K. Cheng, MD, Department of Orthopaedic Surgery, Loma Linda University School of Medicine,
East Campus Ambulatory Services Building, 11406 Loma Linda Drive, Suite 213, Loma Linda, California 92354.md4spine@yahoo.com

Published 31 August 2015.

This manuscript is generously published free of charge by ISASS, the International Society for the Advancement of Spine Surgery. Copyright @ 2015 ISASS. To see more or order reprints or permissions, see http://ijssurgery.com. 